\title{
Caveolin-1 is dispensable for early lymphoid development, but plays a role in the maintenance of the mature splenic microenvironment
}

\author{
Tyler A. Herek ${ }^{1 \dagger}$, Jacob E. Robinson ${ }^{2 \dagger}$, Tayla B. Heavican ${ }^{3}$, Catalina Amador ${ }^{3}$, Javeed lqbal ${ }^{3}$
} and Christine E. Cutucache ${ }^{2^{*}}$

\begin{abstract}
Objective: Caveolin-1 (CAV1) is known for its role as both a tumor suppressor and an oncogene, harboring a highly context-dependent role within a myriad of malignancies and cell types. In an immunological context, dysregulation of CAV1 expression has been shown to alter immunological signaling functions and suggests a pivotal role for CAV1 in the facilitation of proper immune responses. Nonetheless, it is still unknown how Cav1-deficiency and heterozygosity would impact the development and composition of lymphoid organs in mice. Herein, we investigated the impacts of Cav1-dysregulation on the lymphoid organs in young (12 weeks) and aged (36 weeks) Cav1 ${ }^{+/+}$, Cav1 ${ }^{+/-}$, and Cav1 ${ }^{-1-}$ mice.

Results: We observed that only Cav1-deficiency is associated with persistent splenomegaly at all timepoints. Furthermore, no differences in overall body weight were detected (and without sexual dimorphisms). Both aged $\mathrm{Cav1}^{+/-}$and $\mathrm{Cav1}^{-1-}$ mice present with decreased $\mathrm{CD} 19^{+} \mathrm{CD} 22^{+} \mathrm{B}$ cells and secondary-follicle atrophy, specifically in the spleen, compared with wild-type controls and irrespective of splenomegaly status. Consequently, the demonstrated effects on B cell homeostasis and secondary follicle characteristics prompted our investigation into follicle-derived human B-cell lymphomas. Our investigation points toward CAV1 as a dysregulated protein in follicle-derived B-cell malignancies without harboring a differential expression between more aggressive and indolent hematological malignancies.
\end{abstract}

Keywords: Caveolin-1, Immunophenotype, Spleen, B cell

\section{Introduction}

Caveolin-1 (CAV1) is located on chromosome 7q31.2 at the D7S522 locus, a fragile point known to be deleted in certain human cancers [1]. CAV1 is commonly described with a two-faced nature as both a tumor suppressor and an oncogene [2]. This paradox is seen across multiple malignancies as the expression of $C A V 1$ has been shown to be both up- and down-regulated compared to normal

\footnotetext{
*Correspondence: ccutucache@unomaha.edu

${ }^{\dagger}$ Tyler A. Herek and Jacob E. Robinson contributed equally to this work

${ }^{2}$ Department of Biology, University of Nebraska at Omaha, 6001 Dodge St, Omaha, NE 68182, USA

Full list of author information is available at the end of the article
}

tissue, with both phenotypes capable of harboring poor prognoses [2, 3].

With the "Janus-faced" nature of CAV1, researchers have turned to Cav1-deficient mice to sort out the heterogeneity. Cav1 ${ }^{-/-}$mice, but not $\mathrm{Cav1}^{+/-}$mice, harbor a reduced lifespan in comparison to wild-type (WT) controls; however, the reduction in lifespan is not due to an increased frequency of tumorigenic events $[4,5]$. Rather, pulmonary and cardiac complications drive the observed lifespan reduction [4]. It is clear that Cav1 plays a largely context-dependent role, with varied phenotypes seen throughout different organ systems as well as a progression of these phenotypes over time. Nonetheless, it is still unknown how 
Cav1-deficiency and heterozygosity would impact the development and composition of the primary and secondary lymphoid organs of mice. Cav1 is expressed in cells of the immune system $[6,7]$ and plays a vital role in not only immune synapse formation [8] but also in macrophage-, T-, and B-cell signaling [8-14]. While previous studies have investigated Cav1-deficiency in terms of B-cell development [10, 14, 15], T-cell development $[10,11]$, and recently the immunophenotype of the spleen (SP) and bone marrow (BM) in aged mice [14]; no comprehensive study which includes both primary and secondary lymphoid organs, a longitudinal component, and a Cav1-heterozygous experimental population exists.

Consequently, herein we investigated the impact of Cav1 on the lymphoid organ system. Specifically, we addressed how the primary and secondary lymphoid organs of mice can be immunophenotypically described at a young/non-diseased stage (12 weeks) and how the underlying pathologies of Cav1-deficiency impact these organs at near end-of-life (36 weeks).

\section{Main text}

Results

Caveolin-1-deficiency is associated with persistent splenomegaly

We observed no statistically significant differences in body weight $(\mathrm{g})$ across genotypes and timepoints, with no sexual dimorphism (Fig. 1a, Additional file 1: Figure S1a). However, as early as 12 weeks, $\mathrm{Cav1}^{-/}$mice presented with splenomegaly; a finding consistent across all measured timepoints in comparison to WT mice, with $\mathrm{Cav1}^{+/-}$mice mirroring WT mice and no observed sexual dimorphism (Fig. 1b, Additional file 1: Figure S1b).

\section{Caveolin-1 is dispensable for early lymphoid development but critical for $B$ cell maintenance in the spleen}

Investigating the impact of Cav1-deficiency and heterozygosity on B- and T-cell development and homeostasis, we observed no statistically significant differences in the pre/pro B-cell populations, immature B-cell populations, or overall $\mathrm{CD} 19^{+} \mathrm{B}$-cell populations in the $\mathrm{BM}$ nor $\mathrm{CD} 4 / \mathrm{CD} 8$ thymic populations in all experimental groups and time points (Additional
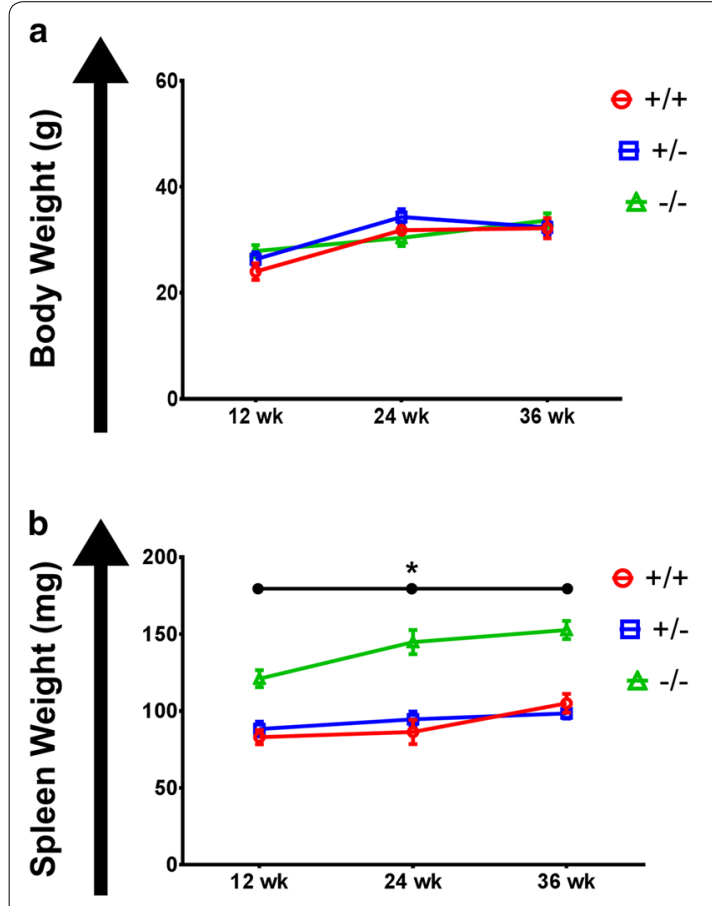

C
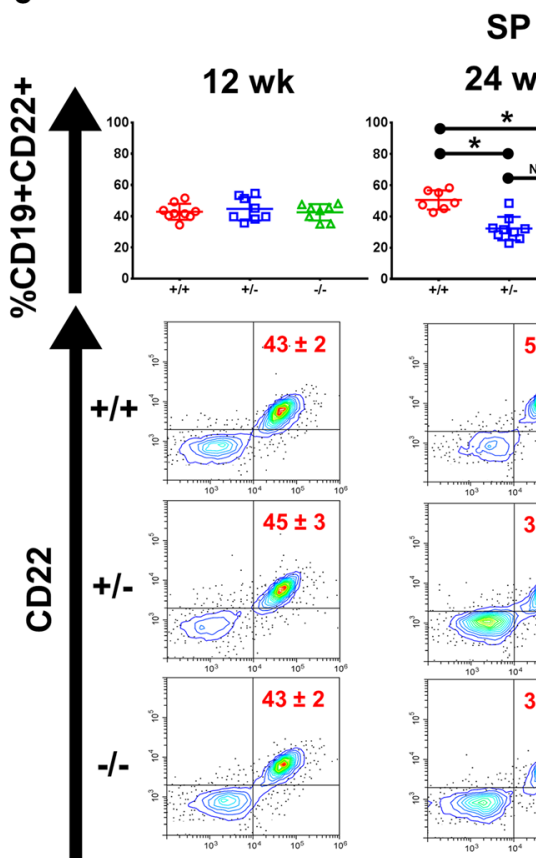

24 wk
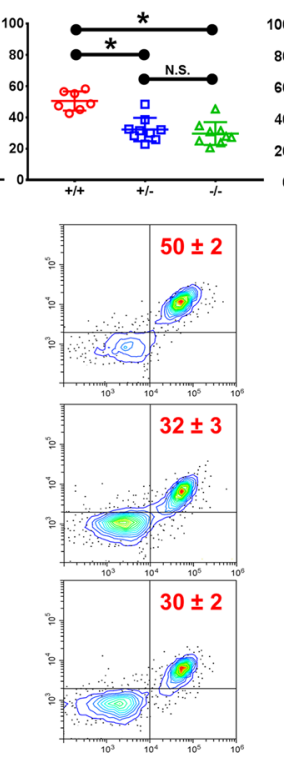

CD19

Fig. 1 Caveolin-1 deficiency is associated with splenomegaly with implications for Caveolin-1 as haploinsufficient for splenic B-cell maintenance. a Line graph of mean body weight (g) of $\mathrm{Cav1}^{+/+}$(red), Cav1 ${ }^{+/-}$(blue), and $\mathrm{Cav1}^{-/-}$(green) mice at indicated timepoint $(\mathrm{n}=9-22 \mathrm{per}$ group). $\mathbf{b}$ Line graph of mean SP weight (mg) of $\mathrm{Cav}^{+/+}$(red), Cav1 ${ }^{+/-}$(blue), and Cav1 ${ }^{-/-}$(green) mice at indicated timepoint $(\mathrm{n}=9-15$ per group). c $($ Top panel) Dot plots for $\mathrm{CD} 19^{+} \mathrm{CD} 22^{+}$B cells in the SP for listed genotypes at 12, 24, and 36 weeks ( $n=7-10$ per group). (Bottom panel) Representative contour flow cytometry plots for $\mathrm{CD} 19^{+} \mathrm{CD} 22^{+} \mathrm{B}$ cells at listed genotypes for listed timepoints. (Line graphs show mean \pm SEM, dot plots show mean \pm SD with each dot corresponding to a biological replicate, flow cytometry gate values show mean \pm SEM, NS not significant, ${ }^{*} p<0.05$ ANOVA and Tukey post hoc test) 
file 2: Figure S2a, b). There were no observed changes in the resident $\mathrm{CD}^{+} \mathrm{T}$-cell populations or skewing of the $\mathrm{CD}^{+}{ }^{+} \mathrm{CD} 4^{+}$versus $\mathrm{CD} 3{ }^{+} \mathrm{CD} 8^{+}$T-cell populations in the thymus (Thy), SP, lymph node (LN), or BM (Additional file 3: Figure S3a, b). Further, we observed no differences in the percentages of mature $B$ cells in the LN or BM at 12 or 36 weeks (Additional file 3: Figure $\mathrm{S} 3 \mathrm{c}$ ).

Conversely, our aged $\mathrm{Cav1}^{-/-}$and $\mathrm{Cav1}^{+/-}$mice exhibited decreased $\mathrm{CD} 19^{+} \mathrm{CD} 22^{+}$B-cell percentages in the SP as early as 24 weeks with corroborative results at 36 weeks (Fig. 1c). Our observation of a decrease in splenic B-cell percentages was seen without any concurrent changes to additionally analyzed white pulp populations, including: $\mathrm{T}$ cells (Additional file 3: Figure S3) or myeloid cells (Additional file 4: Figure S4a-c). With our flow cytometry controlled for cell input, events/sample (see "Methods"), and no change observed in overall lymphoid percentage (Additional file 4: Figure S4d), this excludes the splenomegaly of the Cav1-deficient mice as a confounding factor.

\section{Aged Cav1-transgenic mice exhibit an altered splenic microenvironment}

In response to the observed dysregulation of splenic B-cells in both $\mathrm{Cav1}^{-/-}$and $\mathrm{Cav1}{ }^{+/-}$- mice, we conducted histopathologic analysis on splenic sections from all genotypes. Spleens from 12-week mice showed no differences under routine examination of $\mathrm{H} \& \mathrm{E}$ sections (Fig. 2a) with normal splenic architecture, including: similar frequency of observable secondary follicles (Fig. 2b) as well as mean secondary follicle area (Fig. 2c) in accordance with previous observations [10]. However, at 36 weeks, we noted $\mathrm{Cav1}^{-/-}$and $\mathrm{Cav1}^{+/-}$mice to present with fewer secondary follicles (Fig. 2a, b) with the observed follicles to be smaller in comparison to agematched splenic sections from WT mice (Fig. 2c).

Additional investigation into the proliferative indexes of the 36-week sections revealed no statistically significant differences in $\mathrm{Ki} 67^{+}$cells per field of view (Fig. 2d). Utilizing pentachrome staining we noted an increase in fibrin deposits in the spleens of $\mathrm{Cav1}^{+/-}$and $\mathrm{Cav1}^{-/-}$mice compared to WT spleens (Fig. 2d). No other investigated organs were observed to harbor these deposits. Interestingly, further histopathologic analysis revealed an increase

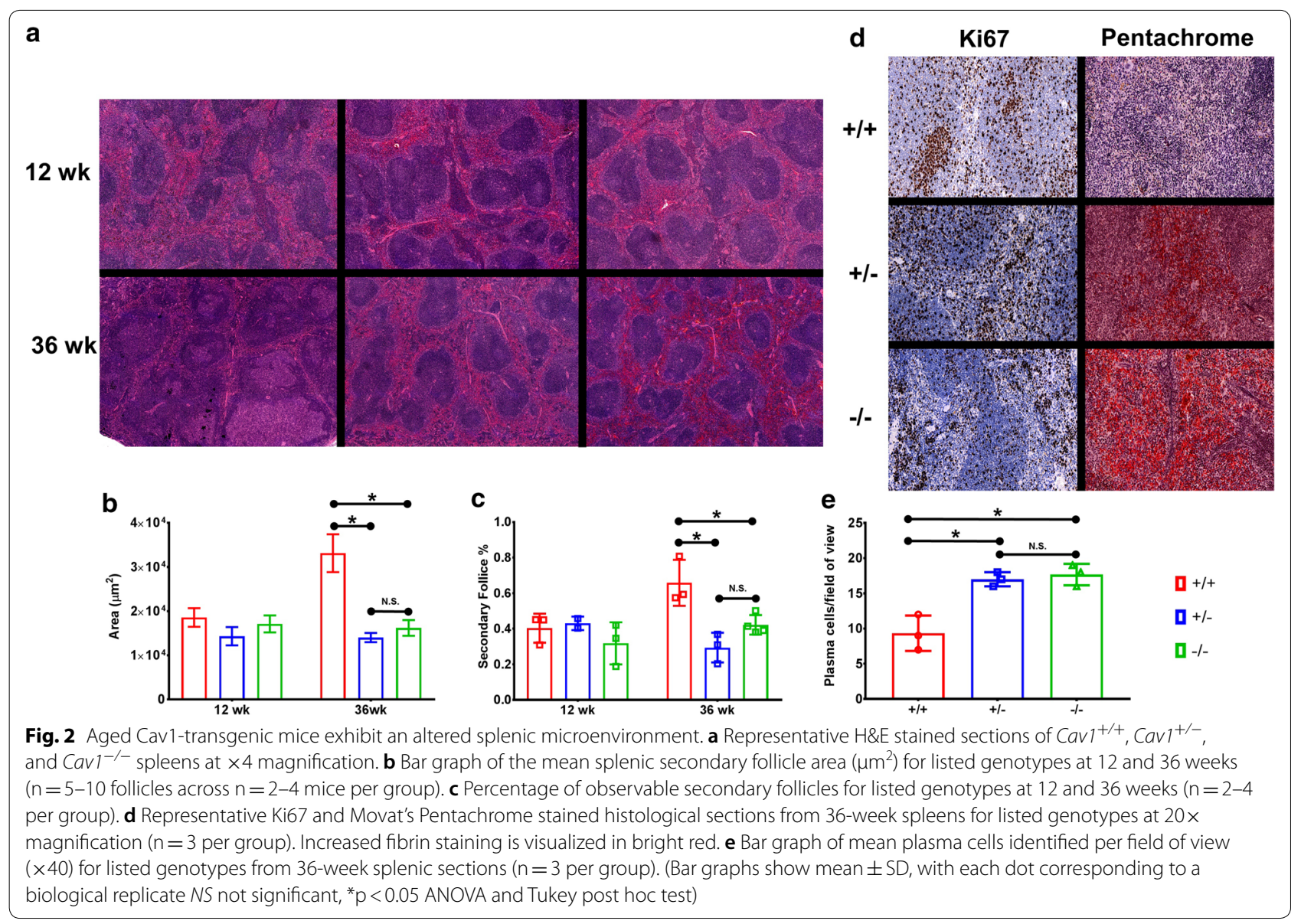


in inter-follicular plasma cells in the spleens of $\mathrm{Cav1} 1^{+-}$ and $\mathrm{Cav1}^{-/-}$mice compared to WT mice (Fig. 2e).

\section{Follicle center B-cell lymphomas display altered CAV1 staining and expression patterns}

Demonstrated above, we observed Cav1 to play a role in the long-term homeostasis of the splenic B-cell population and splenic follicle morphology. We therefore became interested in investigating the expression of CAV1 in post-secondary follicle B-cell malignancies. To this end we scored the Biomax LY6161 tissue microarray for CAV1 staining intensity and localization comparing healthy lymph node samples to both diffuse B-cell lymphoma (DBCL) and follicular lymphoma (FL) samples (Fig. 3a). The distribution of staining scores for disease entities differed in comparison to the normal LNs with fewer B-cell malignancies scored for heavy stromal staining and an increase in those scored for faint blood/lymphatic vessel staining (Fig. $3 \mathrm{~b}$ ). There was no significant difference in the distribution of staining scores when comparing malignancies. Using publicly available microarray data we examined the expression of $C A V 1$ in tumor biopsy samples from FL and two established subtypes of diffuse large B-cell lymphoma (DLBCL), comparing them to normal SP controls. All malignancies analyzed had a lower mean expression of CAV1 compared to the healthy splenic tissue (Fig. 3c).

\section{Discussion}

Herein, we include a characterization of Cav1 in the lymphoid compartments of a murine model. Cav1-deficient mice exhibited persistent splenomegaly compared to Cav1-heterozygous and WT mice. While the mechanism for Cav1-mediated splenomegaly is unknown, we ruled out a higher proliferative index as there were no differences found in $\mathrm{Ki}^{+} 7^{+}$staining numbers between genotypes. Previous investigations found very modest or no persistent differences in proliferation/apoptosis in Cav1-deficient spleens $[5,9,14]$, suggesting a currently unresolved physiological condition may be causing the phenotype. However, a full knockout of Cav1 is required to drive the splenomegaly as our data suggests that Cav1heterozygosity is not sufficient to drive the dysregulation as splenomegaly was not observed in $\mathrm{Cav1}^{+/-}$mice.
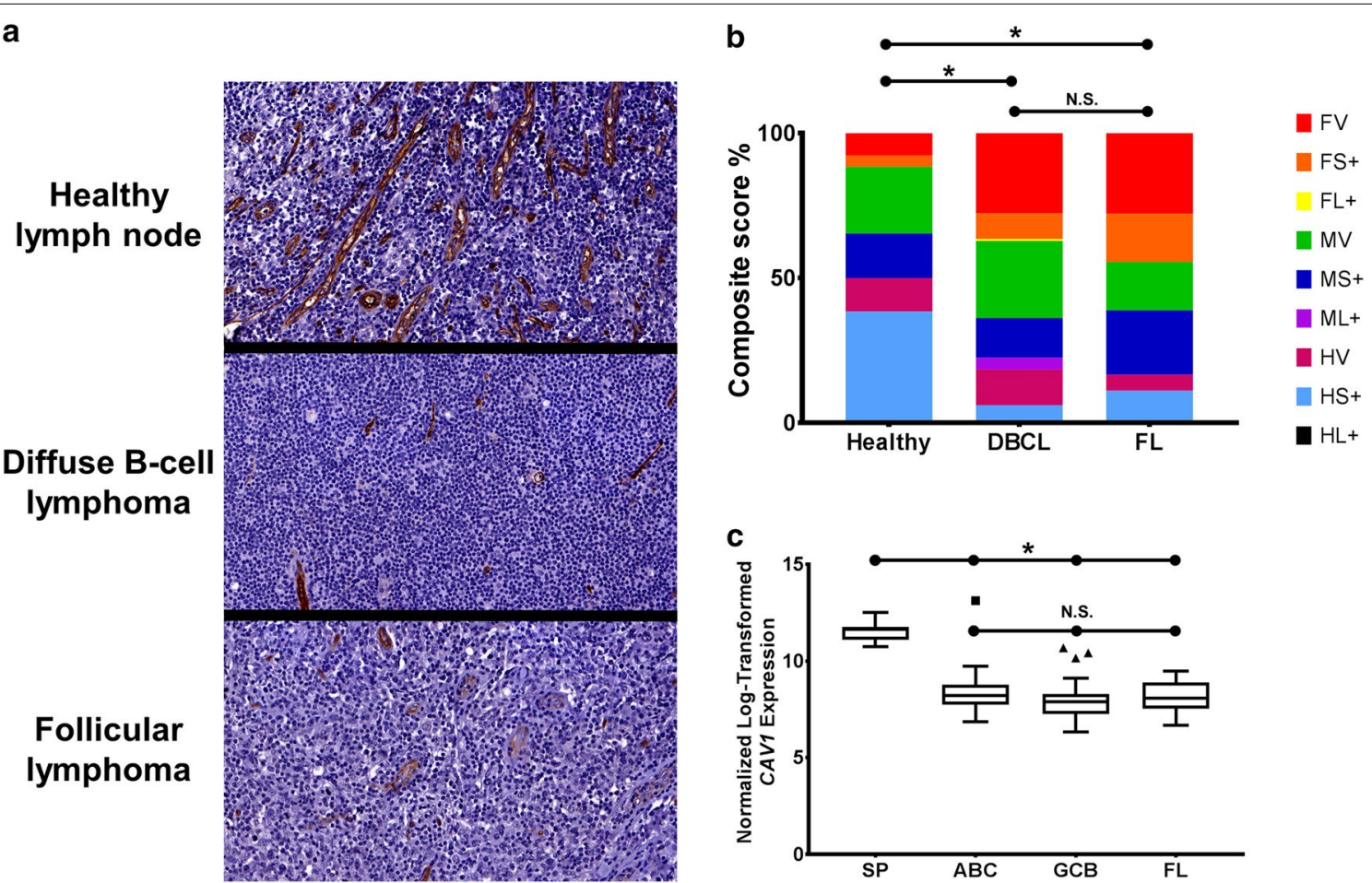

Fig. 3 Follicle center B-cell lymphomas display altered CAV1 staining and expression patterns. a Representative tissue microarray cores stained for CAV1 expression. All images taken at $\times 20$. b Bar graph of the distribution of composite scores assigned to healthy $L N(n=26), D B C L(n=293)$, and FL $(n=18)$ samples for CAV1 staining. $\mathbf{c}$ Boxplot of the normalized log-transformed CAV1 expression value using the 212097_at signal probe for $S P(n=12)$, diffuse large B-cell lymphoma activated B cell-like $(D L B C L-A B C)(n=46)$, diffuse large B-cell lymphoma germinal center $B$ cell-like (DLBCL-GCB) $(n=40)$, and FL $(n=27)$. Line within box represents median, whiskers extend to Tukey lines. (For (b): NS not significant, please see "Methods" for description of scoring key, ${ }^{*} p<0.05$ Kruskal-Wallis and Dunn's multiple comparisons test. For (c): NS not significant, ${ }^{*} p<0.001$ comparison among groups of arrays method) 
Previous investigations have established CAV1 as vital to $\mathrm{T}$-cell function in the context of both antigen presentation and signal transduction [8,11-13]. However, we and others demonstrate that Cav1 is seemingly dispensable for T-cell development and homeostasis [10, 11, 13, 14].

We present data in support of a role for Cav1 in the regulation of $\mathrm{B}$-cell processes by observing a decrease in B-cell percentages, specifically in the SP, in aged Cav1transgenic mice on the $\mathrm{C} 57 \mathrm{BL} / 6$ background utilizing the knockout method described by Razani et al. [16] This decrease was seen in conjunction with aberrant secondary follicle characteristics in aged mice, however a more detailed analysis of these changes is still needed. These findings are highlighted with our observation of a concurrent decrease in splenic B-cell percentages and an increase in inter-follicular plasma cells and fibrin deposits in Cav1-deficient and heterozygous mice without both exhibiting splenomegaly. This suggests that Cav1-heterozygosity is sufficient to drive the dysregulation of B-cell homeostasis and impair the Cav1-mediated internalization of fibrin [17], most likely caused by the angiogenic defects observed in Cav1-transgenic mice [16]. Further, the observation of increased inter-follicular plasma cells may elude to a basis for the decrease in $\mathrm{CD} 19^{+} \mathrm{CD} 22^{+}$(i.e. mature, non-terminally differentiated) $\mathrm{B}$ cells in Cav1-transgenic mice without additionally perturbed populations as plasma cells (mature, terminally differentiated) downregulate pan-B surface markers during differentiation [18, 19]. Collectively, the decrease of mature B cells in conjunction with an increase of fibrin deposits and presence of plasma cells indicate that dysregulation of Cav1 may induce an inflammatory splenic microenvironment.

While there is controversy precise role of Cav1 in B-cell signaling, one point of agreement between all published reports is that there exists a role for Cav1 in B-cell processes as evident by conserved dysregulated responses and changes to physiological populations over time $[14,15]$. However, the lack of consistency in the results derived from established Cav1-knockout models calls into question how the method and selection of exon as well as the genetic background of the mouse contributes to the observed results.

Taken together, the data suggests that loss of Cav1 alone is not sufficient to drive a robust immunological phenotype despite its frequent presence as a dysregulated molecule in human malignancies. However, Cav1-dysregulated cells appear "predisposed" to display aberrant signaling profiles given proper stimuli $[10,11,13-15$, 20-22]. This predisposition, or reprogramming, suggests $C A V 1$ as a facilitator of immune/inflammatory-related processes and could point toward its ultimate role in the progression of multiple human malignancies, including both solid tumor [23-25] and hematological diseases $[8,26,27]$. To this end, we examined the staining pattern of CAV1 and its expression in follicle-derived B-cell malignancies. We observed fainter, less stromal-localized CAV1 staining in the hematological malignancies with lower $C A V 1$ expression in tumor biopsies compared to normal splenic tissue. However, no differences were observed between the more aggressive DLBCL cases when compared to the more indolent FL cases, not forming a parallel between lowered CAV1 expression being associated with a more aggressive disease in both breast [23] and prostate cancer [24]. These results suggest that CAV1 is dysregulated in follicle-derived B cell malignancies but does not play an overt role between more aggressive and indolent disease entities.

\section{Methods \\ Flow cytometry}

Leukocyte populations were isolated using Lympho Separation Medium (MP Biomedicals, USA) with red blood cells lysed using RBC lysis buffer (Alfa Aesar, USA). Cells were counted and checked for viability (>95\%) using Trypan Blue (STEMCELL Technologies, CA) and $10^{6}$ live cells were aliquoted for antibody staining (Additional file 1). Samples were run on a Cytoflex flow cytometer (Beckman Coulter, USA) and analyzed using the CytExpert 2.0 software (Beckman Coulter). Compensation was calculated utilizing a VersaComp antibody capture bead kit (Beckman Coulter). Cells were gated based off forward-side scatter, unstained controls, and fluorescence minus one controls. All samples are representative of at least $5 \times 10^{4}$ events.

\section{Histology}

Animal care protocol found in Additional file 6: Additional methods. Harvested organs were placed into $10 \%$ neutral buffered formalin and allowed to fix for $\geq 72 \mathrm{~h}$ before preservation in $100 \%$ ethanol. Preserved tissues were paraffin-embedded and sectioned $(4 \mu \mathrm{m})$. H\&E and Movat's pentachrome staining were conducted using standard procedures, Ki67 staining using an auto-staining system.

Histological scoring was conducted for Ki67 staining, secondary follicle counting, and plasma cell identification. In each instance, three independent researchers scored the relevant variable in 4 separate fields of view $(\mathrm{n}=3$ per genotype). All slides were viewed at identical magnifications. For scoring agreement metrics and follicle area quantification, please see Additional file 5: Table S1, Additional file 6: Additional methods. 


\section{TMA scoring}

The LY6161 high-density lymphoma and normal lymph node tissue array was utilized as previously described [27]. Cases were scored for both intensity of stain (faint, moderate, heavy) and type of staining observed (vessel only, stromal + vessel, or lymphocyte + stromal + vessel). Patient characteristics and scoring agreement described in Additional file 5: Tables S1, S2.

\section{Gene expression data}

(.CEL) files were downloaded via NCBI Gene Expression Omnibus and uploaded into BRB-ArrayTools. Samples were collated and normalized using the MAS5.0 method. Samples described in Additional file 5: Table S3.

\section{Limitations}

- Unresolved splenomegaly in $C a v 1^{-/-}$mice.

- More in-depth germinal center investigation requires additional IHC markers.

- Higher resolution of B/T-populations could be achieved with additional flow markers.

\section{Additional files}

Additional file 1: Figure S1. (a) Bar graph of mean body (g) of listed genotypes separated by males (no fill pattern) and females (fill pattern) ( $n=3-9$ per group). (b) Bar graph of mean SP weight (mg) of listed genotypes separated by males (no fill pattern) and females (fill pattern) ( $n=2-11$ per group). (Bar graphs show mean $\pm S D$ with each dot corresponding to a biological replicate, NS not significant, ${ }^{*}=p<0.05$ ANOVA and Tukey post hoc test).

Additional file 2: Figure S2. (a) Dots plots of B-cell populations in the $\mathrm{BM}$ for $\mathrm{Cav}^{1 /+}, \mathrm{Cav}^{+/-}$, and $\mathrm{Cav}^{-/-}$mice at 12 and 36 weeks $(\mathrm{n}=8-13$ per group). Pre/Pro $B$ cells designated as $\mathrm{CD} 19^{+} \mathrm{CD}_{22}{ }^{-}$, immature $\mathrm{B}$ cells designated as $\mathrm{CD} 19^{+} \mathrm{CD} 22^{+}$. (b) Representative pseudo-color flow cytometry plots of $\mathrm{CD}_{4}^{+}$and $\mathrm{CD}_{8}^{+}$populations in the Thy at 12 and 36 weeks for listed genotypes. (c) (Dot plots show mean \pm SD with each dot corresponding to a biological replicate, flow cytometry gate values show mean $\pm S D$ )

Additional file 3: Figure S3. (a) Dot plots of $\mathrm{CD}^{+} \mathrm{T}$ cells in the Thy, $\mathrm{BM}, \mathrm{SP}$, and $\mathrm{LN}$ for listed genotypes at 12 and 36 weeks as determined by flow cytometry ( $n=7-13$ per group). (b) Dot plots of $\mathrm{CD}^{+} \mathrm{CD}^{+}$ and $\mathrm{CD}^{+}{ }^{+} \mathrm{CD} 8^{+} \mathrm{T}$ cell populations in the secondary lymphoid organs of listed genotype at 12 and 36 weeks ( $n=4-9$ per group). (c) Dot plots of CD19+ ${ }^{+}$D22 ${ }^{+} B$ cells in the $L N$ for listed genotypes at 12 and 36 weeks $(n=8-11$ per group). (Dot plots show mean \pm SD with each dot corresponding to a biological replicate).

Additional file 4: Figure S4. (a) Dot plots of CD11 $\mathrm{b}^{+}$cells in the SP and $\mathrm{BM}$ at the listed genotypes for 12 and 36 weeks. (b) Dot plots of CD14 ${ }^{+}$ cells in the SP and BM at the listed genotypes for 12 and 36 weeks. (d) Dot plot of splenic lymphocyte percentage in 36-week mice for listed genotypes. (Dot plots show mean \pm SD with each dot corresponding to a biological replicate, NS not significant, ${ }^{*}=p<0.05$ ANOVA and Tukey post hoc test).

Additional file 5: Table S1. Histological scoring table. Table S2. Patient characteristics from the LY6161 high-density lymphoma tissue array. Table S3. Publicly available GEO DataSets utilized for gene expression analysis. Table S4. Antibodies utilized within the study.

Additional file 6. Animal care and secondary follicle area determination methodologies are described.

\section{Abbreviations}

CAV1: Caveolin-1; WT: wild-type; BM: bone marrow; SP: spleen; Thy: thymus; LN: lymph node; H\&E: hematoxylin and eosin; DBCL: diffuse B-cell lymphoma; FL: follicular lymphoma; DLBCL: diffuse large B-cell lymphoma; DLBCL-ABC: diffuse large B-cell lymphoma activated B cell-like; DLBCL-GBC: diffuse large B-cell lymphoma germinal center B cell-like; N.S.: not significant.

\section{Authors' contributions}

TAH, JER, and CEC conceived and designed the research with JI and TBH providing conceptual intellectual guidance and support. TAH and JER performed all experiments. TAH, JER, and CEC analyzed the data and interpreted the results. CA oversaw histopathology with $\mathrm{CA}$ and TBH interpreting the results. TAH and JER prepared figures and drafted the manuscript. All authors read and approved the final manuscript.

\section{Author details}

${ }^{1}$ Eppley Institute, University of Nebraska Medical Center, Omaha, NE, USA. ${ }^{2}$ Department of Biology, University of Nebraska at Omaha, 6001 Dodge St, Omaha, NE 68182, USA. ${ }^{3}$ Department of Pathology and Microbiology, University of Nebraska Medical Center, Omaha, NE, USA.

\section{Acknowledgements}

The authors acknowledge the University of Nebraska Medical Center Tissue Science Facility for their technical services and the Flow Cytometry Research Facility for their help and support. We thank Dr. Greiner for his helpful discussions concerning histopathology. We also thank Dr. George Haddix, the University of Nebraska Foundation, the University of Nebraska Medical Center Eppley Institute for Research in Cancer, and the University of Nebraska at Omaha College of Arts and Sciences.

\section{Competing interests}

The authors declare that they have no competing interests.

\section{Availability of data and materials}

No datasets were generated as a result of the current study. The microarray datasets (GSE57944, GSE3526, GSE7307, GSE25638, GSE23501, GSE25638, GSE35426, GSE16024) utilized in this article are publically available on the Gene Expression Omnibus (https://www.ncbi.nlm.nih.gov/geo/). Further information is provided within Additional file 5: Table S3.

\section{Consent for publication}

Not applicable.

\section{Ethics approval and consent to participate}

All experimental protocols were reviewed and approved per the Institutional Animal Care and Use Committee at the University of Nebraska Medical Center/University of Nebraska at Omaha (IACUC\# 13-056-08),

\section{Funding}

Support for this work was provided by National Science Foundation Graduate Research Fellowship Program (TAH), University of Nebraska at Omaha Sponsored Program Office (FUSE: JER), Dr. George Haddix and the University of Nebraska Foundation (CEC), University of Nebraska at Omaha Department of Biology and the College of Arts and Sciences (CEC). The funders had no role in study design, data collection and analysis, decision to publish, or preparation of the manuscript.

\section{Publisher's Note}

Springer Nature remains neutral with regard to jurisdictional claims in published maps and institutional affiliations.

Received: 9 June 2018 Accepted: 6 July 2018

Published online: 13 July 2018

\section{References}

1. Engelman JA, Zhang XL, Lisanti MP. Genes encoding human caveolin-1 and-2 are co-localized to the D7S522 locus (7q31. 1), a known fragile 
site (FRA7G) that is frequently deleted in human cancers. FEBS Lett. 1998;436:403-10.

2. Quest AFG, Lobos-González L, Nunez S, Sanhueza C, Fernández J, Aguirre A, et al. The caveolin-1 connection to cell death and survival. Curr Mol Med. 2013;13:266-81.

3. Goetz JG, Lajoie P, Wiseman SM, Nabi IR. Caveolin-1 in tumor progression: the good, the bad and the ugly. Cancer Metastasis Rev. 2008;27:715-35.

4. Park DS, Cohen AW, Frank PG, Razani B, Lee H, Williams TM, et al. Caveolin-1 null (-/-) mice show dramatic reductions in life span. Biochemistry. 2003:42:15124-31.

5. Yang G, Timme TL, Naruishi K, Fujita T, Cao G, Rajocopolan K, et al. Mice with cav-1 gene disruption have benign stromal lesions and compromised epithelial differentiation. Exp Mol Pathol. 2008;84:131-40.

6. Fra AM, Williamson E, Simons K, Parton RG. De novo formation of caveolae in lymphocytes by expression of VIP21-caveolin. Proc Natl Acad Sci USA. 1995;92:8655-9.

7. Kiss AL, Túri A, Müllner N, Tímár J. Caveolin isoforms in resident and elicited rat peritoneal macrophages. Eur J Cell Biol. 2000;79:343-9.

8. Gilling CE, Mittal AK, Chaturvedi NK, lqbal J, Aoun P, Bierman PJ, et al. Lymph node-induced immune tolerance in chronic lymphocytic leukaemia: a role for caveolin-1. Br J Haematol. 2012;158:216-31.

9. Li J, Scherl A, Medina F, Frank PG, Kitsis RN, Tanowitz HB, et al. Impaired phagocytosis in caveolin-1 deficient macrophages. Cell Cycle. 2005:4:1599-607.

10. Medina FA, Williams TM, Sotgia F, Tanowitz HB, Lisanti MP. A novel role for caveolin-1 in B lymphocyte function and the development of thymusindependent immune responses. Cell Cycle. 2006;5:1865-71.

11. Tomassian T, Humphries LA, Liu SD, Silva O, Brooks DG, Miceli MC. Caveolin-1 orchestrates TCR synaptic polarity, signal specificity, and function in CD8 T cells. J Immunol. 2011;187:2993-3002.

12. Conroy BD, Herek TA, Shew TD, Latner M, Larson JJ, Allen L, et al. Design, assessment, and in vivo evaluation of a computational model illustrating the role of CAV1 in CD4(+) T-lymphocytes. Front Immunol. 2014;5:599.

13. Schonle A, Hartl FA, Mentzel J, Noltner T, Rauch KS, Prestipino A, et al. Caveolin-1 regulates TCR signal strength and regulatory T-cell differentiation into alloreactive T cells. Blood. 2016;127:1930-9.

14. Minguet S, Klasener K, Schaffer AM, Fiala GJ, Osteso-lbanez T, Raute K, et al. Caveolin-1-dependent nanoscale organization of the BCR regulates B cell tolerance. Nat Immunol. 2017. https://doi.org/10.1038/ni.3813.

15. Bai L, Shi G, Zhang L, Guan F, Ma Y, Li Q, et al. Cav-1 deletion impaired hematopoietic stem cell function. Cell Death Dis. 2014;5:e1140.
16. Razani B, Engelman JA, Wang XB, Schubert W, Zhang XL, Marks CB, et al. Caveolin-1 null mice are viable but show evidence of hyperproliferative and vascular abnormalities. J Biol Chem. 2001;276:38121-38.

17. Guo YH, Hernandez I, Isermann B, Kang TB, Medved L, Sood R, et al. Caveolin-1-dependent apoptosis induced by fibrin degradation products. Blood. 2009;113:4431-9.

18. Kozmik Z, Wang S, Dorfler P, Adams B, Busslinger M. The promoter of the CD19 gene is a target for the B-cell-specific transcription factor BSAP. Mol Cell Biol. 1992;12:2662-72

19. Perfetti V, Vignarelli MC, Bellotti V, Glennie MJ, Zorzoli I, Ubbiali P, et al. Membrane CD22 defines circulating myeloma-related cells as mature or later B cells. Lab Invest. 1997;77:333-44.

20. Pavlides S, Tsirigos A, Migneco G, Whitaker-Menezes D, Chiavarina B, Flomenberg $\mathrm{N}$, et al. The autophagic tumor stroma model of cancer: role of oxidative stress and ketone production in fueling tumor cell metabolism. Cell Cycle. 2010;9:3485-505.

21. Garrean S, Gao XP, Brovkovych V, Shimizu J, Zhao YY, Vogel SM, et al. Caveolin-1 regulates NF-kappaB activation and lung inflammatory response to sepsis induced by lipopolysaccharide. J Immunol. 2006;177:4853-60.

22. Yuan K, Huang C, Fox J, Gaid M, Weaver A, Li G, et al. Elevated inflammatory response in caveolin-1-deficient mice with Pseudomonas aeruginosa infection is mediated by STAT3 protein and nuclear factor KB (NF-kappaB). J Biol Chem. 2011;286:21814-25.

23. Li X, Sun J, Hu S. Expression of caveolin-1 in breast cancer stroma as a potential prognostic biomarker of survival and progression: a metaanalysis. Wien Klin Wochenschr. 2017;129:558-63.

24. Ayala G, Morello M, Frolov A, You S, Li R, Rosati F, et al. Loss of caveolin-1 in prostate cancer stroma correlates with reduced relapse-free survival and is functionally relevant to tumour progression. J Pathol. 2013;231:77-87.

25. Chatterjee M, Ben-Josef E, Thomas DG, Morgan MA, Zalupski MM, Khan $G$, et al. Caveolin-1 is associated with tumor progression and confers a multi-modality resistance phenotype in pancreatic cancer. Sci Rep. 2015;5:10867.

26. Sasaki H, Nishikata I, Shiraga T, Akamatsu E, Fukami T, Hidaka T, et al. Overexpression of a cell adhesion molecule, TSLC1, as a possible molecular marker for acute-type adult T-cell leukemia. Blood. 2005;105:1204-13.

27. Herek TA, Shew TD, Spurgin HN, Cutucache CE. Conserved molecular underpinnings and characterization of a role for caveolin-1 in the tumor microenvironment of mature T-cell lymphomas. PLOS ONE. 2015;10:e0142682.
Ready to submit your research? Choose BMC and benefit from:

- fast, convenient online submission

- thorough peer review by experienced researchers in your field

- rapid publication on acceptance

- support for research data, including large and complex data types

- gold Open Access which fosters wider collaboration and increased citations

- maximum visibility for your research: over $100 \mathrm{M}$ website views per year

At BMC, research is always in progress.

Learn more biomedcentral.com/submissions 